\title{
Curcumin From Traditional Iranian Medicine to Molecular Medicine
}

\author{
Hamid Reza Rahimi ${ }^{1, *}$; Reza Kazemi Oskuee ${ }^{2}$ \\ ${ }^{1}$ Student Research Committee, Department of Modern Technologies and New Sciences, Mashhad University of Medical Sciences, Mashhad, IR Iran \\ ${ }^{2}$ Department of Medical Biotechnology, Neurogenic Inflammation Research Center, Mashhad University of Medical Sciences, Mashhad, IR Iran \\ ${ }^{*}$ Corresponding author: Hamid Reza Rahimi, Department of Modern Technologies and New Sciences, Mashhad University of Medical Sciences, Azadi Square, Pardis Campus, Mash- \\ had, IR Iran. Tel: +98-5118002301, Fax:+98-5118002287, E-mail: rahimihr891@mums.ac.ir
}

Received: May 4, 2014; Accepted: May 5, 2014

Keywords: Curcumin; Medicine, Traditional; Molecular Medicine

More than 2000 years, turmeric has been used in traditional medicine in Iran and some other Asian countries (1), Avicenna (980-1037 AD) recommended mixture of turmeric and lamb tallow as a topical anti-inflammatory and pain relieving agent (2). In Indian, traditional medicine has been used as topical treatment for wound healing, bites, burns, acne and some other conditions such as dental diseases, dyspepsia and antacid $(3,4)$.

The spice turmeric (in Farsi Zardchobeh) has a very active component called curcumin. Curcumin is an anti-inflammatory and chemopreventive molecule (5). Diferuloylmethane or (1E, 6E)-1, 7-bis (4-hydroxy-3-methoxyphenyl)-1, 6-heptadiene-3, 5-dione is a chemical name of curcumin (Figure 1) $(3,6)$.

Recent clinical and experimental studies showed antioxidant, anti-inflammatory, chemopreventive, and chemotherapeutic activity of curcumin during the past 20 years $(7,8)$. Nuclear factor $\kappa \mathrm{B}(\mathrm{NF}-\mathrm{\kappa B})$ signaling pathway is one of the most important pathways in the cellular and molecular inflammation $(9,10)$. In this cellular signaling pathway, cytokines and adhesion molecules are secreted (11). According to the molecular studies, curcumin inhibit NF- $\mathrm{B}$ signaling pathway and could regulate cytokines production and influence immune response (12, 13). Curcumin has suppressed some genes expression, especially cytokines genes. Curcumin could down regulate the expression of TNF $\alpha$, IL-1, IL-6, IL-8, adhesion molecules (ICAM, VCAM), C-reactive protein (10).

That is why Iranian traditional medicine was recommended the topical mixture of turmeric in articular pain relieving and articular swelling due to NF- $\mathrm{BB}$ inhibition. Same molecular mechanism is found in topical nonsteroidal anti-inflammatory drugs (NSAIDs). Any human chronic inflammatory diseases such as asthma, bronchitis, inflammatory bowel disease, rheumatoid arthritis,<smiles>COc1cc(/C=C/C(=O)/C=C(O)/C=C/c2ccc(O)c(OC)c2)ccc1O</smiles>

Figure 1. The Chemical Structure of Curcumin

coronary artery disease, atherosclerosis plaque stabilizing, diabetes mellitus, obesity, fatty liver, metabolic syndrome, depression, cancer, and allergy could be a therapeutic target of curcumin (10). However, bioavailability and drug delivery method of curcumin are impediment in modern pharmacology. Absorption of curcumin in human gastrointestinal tract is very difficult.

Many researchers are focussing on molecular and cellular aspects of curcumin activities (14), some others are focussing on curcumin delivery methods (15). Some new drug delivery methods such as curcumin nanoparticles and liposomal curcumin are considered (15). Unpublished data in our department in Mashhad University of Medical Sciences show acceptable bioavailability of Curcumin-derivative nanomicelles in comparison with curcumin capsules. The spice turmeric is our medical heritage of the centuries; this wonderful natural product has a great secret, which is an inhibitory effect on chronic inflammation without significant side effect. Curcumin, active component of this spice, could be an example of targeted therapy that was made by nature. We have to explore curcumin cellular and molecular targets.Acknowledgements

\section{Acknowledgements}

There are no acknowledgements. 


\section{Authors' Contribution}

All author contribute the same.

\section{Financial Disclosure}

There is no financial interest.

\section{Funding/Support}

There is no funding source.

\section{References}

1. Ammon HP, Wahl MA. Pharmacology of Curcuma longa. Planta Med.1991;57(1):1-7.

2. Library CoM. The Canon of Medicine of Avicenna. Classics of Medicine Library; 1984.

3. Hatcher H, Planalp R, Cho J, Torti FM, Torti SV. Curcumin: from ancient medicine to current clinical trials. Cell Mol Life Sci. 2008;65(11):1631-52.

4. Shamsara J, Ramezani M, Mohammadpour AH. Curcumin as a novel plaque stabilizing agent in prevention of acute coronary syndrome. Iran J Med Hypotheses Ideas. 2009;3:1-6.

5. Chainani-Wu N. Safety and anti-inflammatory activity of curcumin: a component of tumeric (Curcuma longa). J Altern Complement Med. 2003;9(1):161-8.

6. Santel T, Pflug G, Hemdan NY, Schafer A, Hollenbach M, Buchold $\mathrm{M}$, et al. Curcumin inhibits glyoxalase 1: a possible link to its anti- inflammatory and anti-tumor activity. PLoS One. 2008;3(10).

7. Menon VP, Sudheer AR. Antioxidant and anti-inflammatory properties of curcumin. Adv Exp Med Biol. 2007;595:105-25.

8. Sandur SK, Pandey MK, Sung B, Ahn KS, Murakami A, Sethi G, et al. Curcumin, demethoxycurcumin, bisdemethoxycurcumin, tetrahydrocurcumin and turmerones differentially regulate anti-inflammatory and anti-proliferative responses through a ROSindependent mechanism. Carcinogenesis. 2007;28(8):1765-73.

9. Thangapazham RL, Sharma A, Maheshwari RK. Multiple molecular targets in cancer chemoprevention by curcumin. AAPS J. 2006;8(3):E443-9.

10. Aggarwal BB, Harikumar KB. Potential therapeutic effects of curcumin, the anti-inflammatory agent, against neurodegenerative, cardiovascular, pulmonary, metabolic, autoimmune and neoplastic diseases. Int JBiochem Cell Biol. 2009;41(1):40-59.

11. Miyake T, Aoki M, Shiraya S, Tanemoto K, Ogihara T, Kaneda Y, et al. Inhibitory effects of NFkappaB decoy oligodeoxynucleotides on neointimal hyperplasia in a rabbit vein graft model. J Mol Cell Cardiol. 2006;41(3):431-40.

12. Prasad S, Tyagi AK, Aggarwal BB. Recent Developments in Delivery, Bioavailability, Absorption and Metabolism of Curcumin: the Golden Pigment from Golden Spice. Cancer Res Treat 2014;46(1):2-18.

13. Zhou H, Beevers CS, Huang S. The targets of curcumin. Curr Drug Targets. 2011;12(3):332-47.

14. Shehzad A, Lee YS. Molecular mechanisms of curcumin action: signal transduction. Biofactors. 2013;39(1):27-36

15. Helson L. Curcumin (diferuloylmethane) delivery methods: a review. Biofactors. 2013;39(1):21-6. 